\title{
BMJ Open Puff or pass: do social media and social interactions influence smoking behaviour of university students? A cross-sectional mixed methods study from Dhaka, Bangladesh
}

\author{
Naym Uddin Roby (D) , ${ }^{1,2}$ M Tasdik Hasan, ${ }^{2,3}$ Sahadat Hossain (D) , ${ }^{4}$ \\ Enryka Christopher, ${ }^{5}$ Md Kapil Ahmed, ${ }^{1}$ Ariful Bari Chowdhury, ${ }^{1}$ Shahriar Hasan, ${ }^{1}$ \\ Fatema Ashraf ${ }^{2,6}$
}

To cite: Roby NU, Hasan MT, Hossain S, et al. Puff or pass: do social media and social interactions influence smoking behaviour of university students? A cross-sectional mixed methods study from Dhaka, Bangladesh. BMJ Open 2020;10:e038372. doi:10.1136/ bmjopen-2020-038372

- Prepublication history for this paper is available online. To view these files, please visit the journal online (http://dx.doi. org/10.1136/bmjopen-2020038372).

NUR and MTH contributed equally.

NUR and MTH are joint first authors.

Received 19 March 2020 Revised 16 July 2020 Accepted 04 October 2020

Check for updates

(C) Author(s) (or their employer(s)) 2020. Re-use permitted under CC BY-NC. No commercial re-use. See rights and permissions. Published by BMJ.

For numbered affiliations see end of article.

Correspondence to Dr Naym Uddin Roby; dr.nyroby@gmail.com

\section{ABSTRACT}

Objective To determine whether the odds of being a smoker differ based on social media use and social interactions among urban university students in Bangladesh.

Hypothesis Social media use and social interactions influence the smoking behaviour of Bangladeshi university students, particularly in starting and maintaining cigarette smoking. Design and setting A cross-sectional study using mixed methods on 600 student smokers and non-smokers recruited from two public and two private universities in Dhaka, Bangladesh, a lower middle-income country with limited resources. Exclusion criteria were those who did not use any form of social media and PhD students.

Results Odds of smoking were significantly higher for those who socialised more than 4 hours/day ( $p<0.05$; OR 1.75; 95\% $\mathrm{Cl} 1.12$ to 2.75 ) and typically at night ( $\mathrm{p}<0.05 ; 0 \mathrm{R} 2.80 ; 95 \% \mathrm{Cl}$ 1.95 to 4.00). Odds of smoking were also higher for those who liked ( $p<0.05 ; 0 R 4.85 ; 95 \% \mathrm{Cl} 3.32$ to 7.11$)$, shared $(p<0.05$; OR 20.50; 95\% Cl 13.02 to 32.26) and followed ( $<<0.05$; OR 2.88; $95 \% \mathrm{Cl} 1.36$ to 6.11 ) tobacco-related content on social media. Qualitative analysis resulted in emergent themes of smokers imitating tobacco-related photos or videos seen on social media and peers as an influence for smoking initiation. Conclusion This study suggests social media and social interactions may influence smoking behaviour in university students in Dhaka, Bangladesh. Future research should continue to investigate the roles social media and social interaction have on smoking in order to explore social mediabased smoking cessation interventions or dissemination of smoking health hazards through social media.

\section{INTRODUCTION}

Smoking, a global public health concern, is one of the major lifestyle risk factors for multiple adverse health conditions. The WHO estimates that smoking-induced and other tobaccoinduced diseases lead to approximately 6 million deaths annually. ${ }^{1}$ By 2030, 8.3 million deaths worldwide will be attributed to these diseases, representing $10 \%$ of deaths globally. ${ }^{2}$ The global WHO report estimates $24.9 \%$ of people aged 15
Strengths and limitations of this study

- Associations between smoking behaviour and social media and social interactions have not been studied previously in Bangladeshi university students.

- The mixed methods design used both quantitative and qualitative data to generate a more nuanced and deeper understanding of factors influencing smoking behaviour that would not have been captured with either of these two methods alone.

- Resource constraints limited the ability to conduct in-depth interviews and focus group discussions, which would have allowed a more detailed exploration of factors underlying initiation or continuation of smoking.

- Limited funding limited the location of data collection, thus data on students studying in rural universities in other areas of the country were not captured.

- The self-report nature of the survey could have introduced reporting bias, as respondents may not have responded truthfully due to stigma associated with smoking.

years and older are using tobacco in some form or another. Among young people aged 15-24 years, the average rate of tobacco use was $17 \%$ in 2015. Globally, $19.8 \%$ of people smoke tobacco, with a significant number of these smokers in Southeast Asia. According to the Global Youth Tobacco Survey, the Southeast Asian region has the largest number of child tobacco users at 14.8 million or $34 \%$ of the global total. Adolescents from high-income countries have lower prevalence rates of general tobacco use than those from lower middle-income countries. ${ }^{3}$ The incidence rate of smoking remains high among adolescents, with a decrease in the age of onset over time. ${ }^{4}$ Studies suggest that a substantial number of smokers among young populations pick up the habit while in university. ${ }^{5-7}$ Nazary 
et al. reports that $43.5 \%$ of university students start smoking during their time at university. ${ }^{8}$

In contrast to many developed countries, smoking in Bangladesh, a lower middle-income country, is currently not banned in most public places. Hence, smokers are not under any societal pressure to quit smoking. Bangladesh is one of the largest tobacco-consuming countries in the world. ${ }^{1}$ The WHO estimates that almost a quarter of Bangladesh's population were smokers in 2010 , with $46 \%$ of men smoking and about $1 \%$ of women smoking. ${ }^{1}$ The country's prevalence rate declined in 2017 to $18 \%$; however, there was a rise in the percentage of smokers among the male population. ${ }^{9}$ This reduction is the result of certain initiatives like policy implication, increased taxation and community-based interventions. ${ }^{10-12}$ Moreover, $17.3 \%$ of Bangladeshi smokers are aged between 15 and 24 years. ${ }^{1}$ One study suggests a rising prevalence in smoking among university students in the Sylhet Division of Bangladesh, with almost half of their male student sample being smokers. ${ }^{13}$ In addition, peer influence is one of the pivotal causes for both initiation and continuation of cigarette smoking among school and college students. ${ }^{14} 15$ Similarly, it is also regarded as the prime factor for smoking among Bangladeshi university students. ${ }^{16}{ }^{17}$ Media is increasingly used to spread knowledge about tobacco usage, as one study cites over half of adults notice tobacco advertised in different medias, including social media. ${ }^{9}$ Social media are web-based platforms that are a popular way to share information with a broad audience in the modern day, as anyone can create content to disseminate globally. The Bangladesh Telecommunication Regulatory Commission reports the total number of internet subscribers at 93.3 million in 2019, with Facebook being the most used social media. ${ }^{18}$ Tobacco companies use Facebook, Wikipedia and YouTube for promotional activities, with sales promotion most prevalent on YouTube. ${ }^{19}$ Major US tobacco companies increased expenditures on internet marketing from $\$ 125000$ in 1998 to $\$ 23.3$ million in $2014 .^{20} \mathrm{~A}$ majority of university students use social media, rife with possibilities of watching tobacco companies' posts in their feed. ${ }^{21}$ Unsurprisingly, online tobacco advertising viewed by adolescents increased from $25.9 \%$ in 2000 to $44.7 \%$ in $2011 .{ }^{22}$ Understanding whether and how social media affects smoking behaviour among youth is imperative to creating interventions. However, in Bangladesh, there are no such data on the impact of social media on smoking.

As internet use becomes more widespread among Bangladeshi youth, many of whom are studying in universities, there may be a possibility of social media influencing this population to engage in smoking. On the other hand, adolescents have reported influence from peers on their initiation and continuation of cigarette smoking. ${ }^{2324}$ Many university students may also be influenced by their peers at and during the 'adda', which in Bangladeshi culture refers to both the locations a group of like-minded individuals congregate as well as the intellectual exchanges that take place when an adda forms. As addas are social affairs, with smokers often mixing with non-smokers, those who do not smoke are not only exposed to passive smoking, but sometimes even influenced to "try a puff." Understanding the extent to which both social media and in-person peer pressure affect smoking behaviour in youth behoves public health campaigns aiming to reduce global smoking rates. The purpose of this study is to assess whether the odds of being a smoker differ based on social media use and social interaction behaviour among university students in urban Dhaka.

\section{METHODOLOGY}

\section{Study design}

This was a mixed methods study using a cross-sectional design and semistructured interviews between March and November 2017 among university students of two public and two private universities in Dhaka city. The two public universities were University of Dhaka and Jahangir Nagar University, and the two private universities were North South University and American International University-Bangladesh. The estimated sample size of 600 was calculated based on the $23 \%$ prevalence estimate of tobacco smoking among the general population. ${ }^{25-27}$ A pretested structured interview was used to collect data for the quantitative assessment. University students aged 18 and older who use at least one form of social media via mobile, tablet or computer were included. Exclusion criteria were those who did not use at least one form of social media and students who were enrolled in a $\mathrm{PhD}$ or other doctoral-level degrees. Both smokers and non-smokers were included for the quantitative component of this study, while the qualitative component included only smokers.

\section{Sampling}

A systematic random sampling technique was used to select the students from different sections of the science, arts and commerce subjects. Attendance directories of the students in different classes were collected from class teachers as a sampling frame. The sample size was calculated with Fisher's statistical formula for determining a sample size for a crosssectional study.

$$
\mathrm{n}=\frac{\mathrm{Z} 2 \mathrm{p}(1-\mathrm{p})}{\mathrm{d}^{2}}
$$

Where:

$\mathrm{n}=$ the required sample size.

$\mathrm{Z}=$ critical value associated with the level of confidence. A 95\% confidence level was used. This corresponds to a $\mathrm{Z}$ value of 1.96 .

$\mathrm{d}=$ precision $/$ margin of error, set at 0.05 (5\% margin of error).

$\mathrm{p}=$ prevalence
population. ${ }^{25-27}$ of smoking, $0.23 \quad(23 \%)$ for the

Based on this calculation, the sample size was 276, which was increased to 300 considering about a $10 \%$ non-response rate. This sample was determined based on private universities. Based on this sample size, 300 students were also added from public universities. While this approach was not ideal, as students from private university tend to be more socioeconomically homogenous than those attending public university, the limited time and resources of the authors of this study necessitated this smaller estimation. However, as the topic of this study, tobacco smoking, is so widespread among this age 
group, any adverse impact of this underestimation is likely to be negligible. Therefore, the total sample was $300 \times 2=600$, which was equally distributed $(300+300)$ between public and private universities as follows:

- University of Dhaka-150 participants.

- Jahangirnagar University-150 participants.

- North South University-150 participants.

- American International University of Bangladesh-150 participants.

For the qualitative assessment, 12 students (three from each university) who were smokers that used social media were selected. The samples for this assessment were chosen purposively considering the time, availability and feasibility of research staff. As the aim of the qualitative component was to find insights on initiation of and reasons behind smoking, only smokers were included. Sampling for this qualitative portion of the study was done by the research assistants (RAs) asking the first four to five eligible participants of the quantitative portion whether they were interested in being contacted about another interview for the study after their first interview. Those who agreed were then followed up by the principal investigator (PI) of the study to confirm eligibility and arrange an interview. The first three eligible participants (from each university) to complete qualitative interviews were included in the qualitative sample.

\section{Data collection method and tools}

The questionnaire was constructed based on input from the research team on what type of questions would be most beneficial in addressing the research question. Social media use made up one section, with questions regarding what social media platform was preferred, how long participants had been using social media, what time of day they typically used social media and whether or not they interacted with tobacco-related content, including liking, following, or sharing content. Social interaction was another section, with questions regarding length and time of day participants typically spent with peers and the role peer pressure played in smoking behaviour. The interview lasted approximately 15-20minutes. Pretesting (on 5\% of the sample) for the instrument was done to ensure validity, reliability, accuracy, and cultural and linguistic appropriateness of the questionnaire. Results of this pilot indicated minor changes were necessary to the language of some questions in order to improve clarity and understanding, which were then modified based on feedback from the pretest participants.

Face-to-face interviews using a semistructured instrument were conducted by eight RAs to collect data for the quantitative methods. The recruited RAs were trained on the objectives of this research and how to approach respondents in order to ensure quality data collection. Interviews were conducted in various study areas where the respondents were comfortable, such as classrooms, tea stalls, libraries, canteens, hostels, and so on. The RAs were equally distributed among the universities (two RAs per university) and started collecting data simultaneously from the four universities. Throughout data collection, completed questionnaires were crosschecked by one of the investigators as a quality control measure.
For the qualitative methods, 12 brief qualitative interviews using a brief topic guide were conducted with three students from each of the four universities. The brief topic guide included open-ended questions on participants' thoughts and reflections on the role social media played in their decisions to start or continue smoking. Another set of open-ended questions regarded participants' thoughts and reflections on the role their friends, acquaintances and other peers played in their decisions to start or continue smoking. In addition to having a written record of each interview, all interviews were recorded with respondents' consent. Recordings were then transcribed by two study team members and checked by the PI and co-PI on a regular basis. After the qualitative data were analysed thematically by research staff, the resulting themes were discussed with the PI to ensure that interpretations aligned with the interviews. Final themes were a result of this iterative process. Atlas.ti software was used for managing qualitative data.

\section{Data analysis}

The collected data were cleaned, separated, and entered by RAs and quality checked by the PI regularly. SPSS V.20.0 software was used for all statistical analyses. Pearson's $\chi^{2}$ test, Fisher's exact test, and multivariate logistical regressions were used to evaluate the associations between the variables. Statistical significance was accepted at the 0.05 level.

\section{Ethical consideration}

Prior to the start of the interview, participants were read an overview of the study and study procedures, and then given a chance to ask any clarifying questions. Interviewers were trained to explain the study in lay terms and take notice of any suggestion that participants did not understand the study context or procedures involved. Once verbal consent was obtained after these steps, an official written consent form was read to each participant and signed after confirmation of consent given. Ethical standards followed the guidance of the 2013 revision of the Helsinki Declaration. ${ }^{28}$ All interviews were conducted in private spaces within study areas respondents felt comfortable in. Qualitative interviews followed the same procedures, with the addition of consent to be recorded included in the written consent as well as on the voice recording itself.

\section{Patient and public involvement}

No patient was involved.

\section{RESULTS}

\section{Quantitative findings}

Participants

Respondents included 600 students from four universities in the Dhaka division. Of the 600 students, $75.2 \%$ were male and $24.8 \%$ were female. Their ages were between 
Table 1 Sociodemographic characteristics of participants, by smoking status

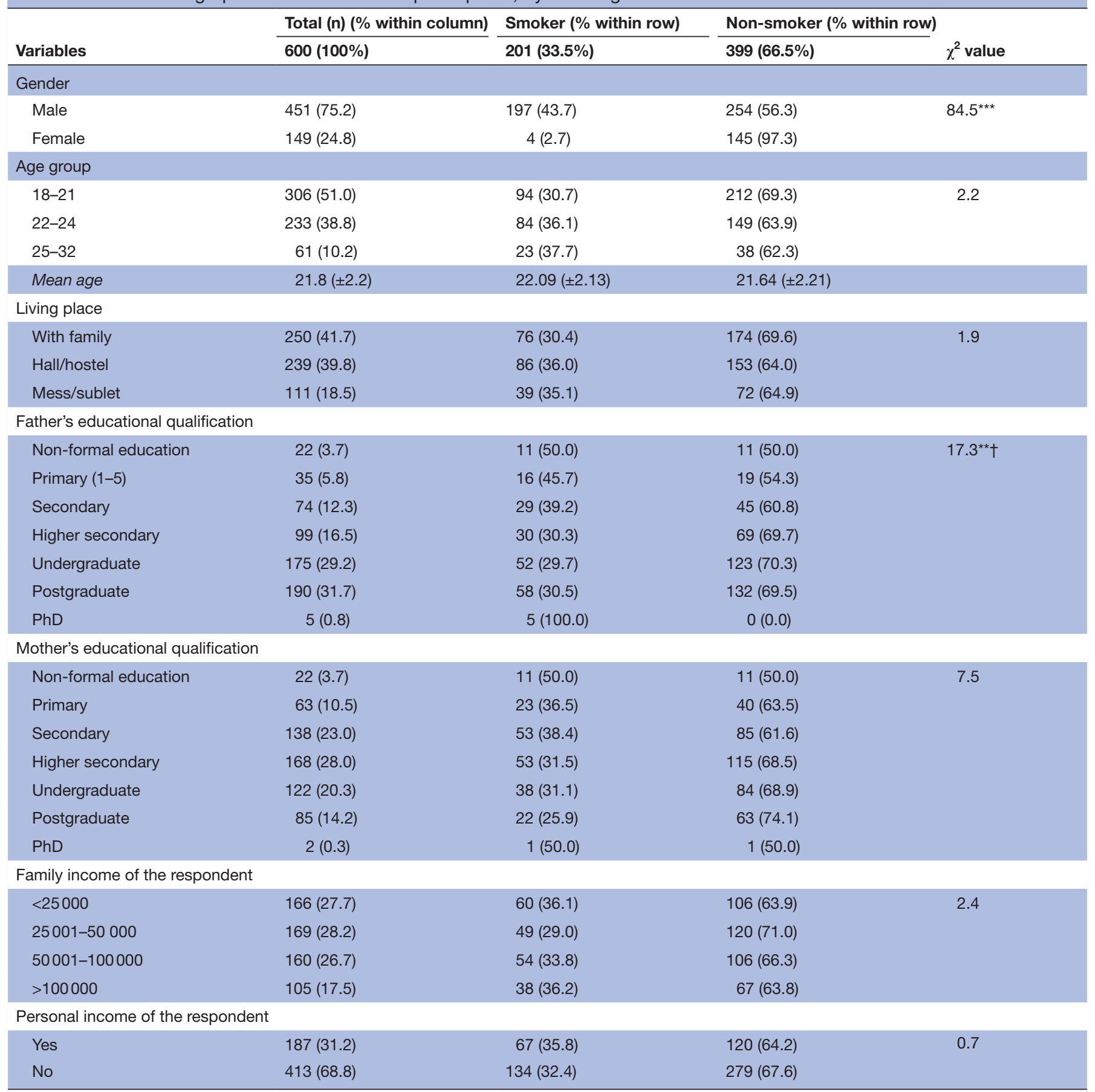

$\mathrm{n}=600$.

${ }^{* *} \mathrm{P}<0.01 ;{ }^{* * *} \mathrm{P}<0.001$.

†P value is based on Fisher's exact test.

18 and 32 years, and the mean age of respondents was $21.8 \pm 2.2$ years (table 1 ).

Prevalence of smoking

The overall prevalence estimate of tobacco smoking was $33.5 \%$ among the study participants. $\chi^{2}$ tests of association between smoking status and sociodemographic characteristics of the participants show that $43.7 \%$ of male students were smokers, while only $2.7 \%$ of female students were smokers (table 1). This difference between the ratio of smokers to non-smokers among male and female students was statistically significant $\left(\chi^{2}=84.5\right.$, $\mathrm{p}<0.001)$. Fisher's exact test indicated that father's education was also significantly associated $(\mathrm{p}<0.01)$ with student smoking behaviour, with more smokers among those whose fathers have lower education than those whose fathers have higher education. 
Table 2 Association of social media use with smoking

\begin{tabular}{|c|c|c|c|c|}
\hline \multirow[b]{2}{*}{ Variables } & Total (n) & Smoker & Non-smoker & \multirow[b]{2}{*}{$\chi^{2}$ value } \\
\hline & (\% within column) & (\% within row) & (\% within row) & \\
\hline & $600(100 \%)$ & $201(33.5 \%)$ & $399(66.5 \%)$ & \\
\hline Facebook & $438(73.0)$ & $132(30.1)$ & 306 (69.9) & $9.105^{\star}$ \\
\hline YouTube & $131(21.8)$ & $58(44.3)$ & $73(55.7)$ & \\
\hline
\end{tabular}

Duration of social media use (years)

$\begin{array}{lrrr}\leq 5 & 137(22.8) & 31(22.6) & 106(77.4) \\ >5 & 463(77.2) & 170(36.7) & 293(63.3)\end{array}$

Typical time of day for social media use

$\begin{array}{lrrr}\text { Daytime } & 67(11.2) & 13(19.4) & 54(80.6) \\ \text { Night-time } & 533(88.8) & 188(35.3) & 345(64.7)\end{array}$

Liked/followed TAPS-related picture/image on social media

$\begin{array}{lrrr}\text { Yes } & 231(38.5) & 122(52.8) & 109(47.2) \\ \text { No } & 369(61.5) & 79(21.4) & 290(78.6)\end{array}$

Shared TAPS-related picture/image on social media

$\begin{array}{lrrr}\text { Yes } & 201(33.5) & 148(73.6) & 53(26.4) \\ \text { No } & 399(66.5) & 53(13.3) & 346(86.7)\end{array}$

Liked/followed TAPS-related video on social media

$\begin{array}{llcc}\text { Yes } & 237(39.5) & 131(55.3) & 106(44.7) \\ \text { No } & 363(60.5) & 70(19.3) & 293(80.7)\end{array}$

Shared TAPS-related video on social media

$\begin{array}{cccc}\text { Yes } & 205(34.2) & 153(74.6) & 52(25.4) \\ \text { No } & 395(65.8) & 48(12.2) & 347(87.8)\end{array}$

Followed/joined any groups related to smoking on social media

\begin{tabular}{cccc} 
Yes & $32(5.3)$ & $19(59.4)$ & $13(40.6)$ \\
No & $568(94.7)$ & $182(32.0)$ & $386(68.0)$ \\
\hline
\end{tabular}

$\mathrm{n}=600$.

${ }^{*} \mathrm{P}<0.05 ;{ }^{* *} \mathrm{p}<0.01 ;{ }^{* * *} \mathrm{p}<0.001$.

TAPS, tobacco advertising, promotion and sponsorship.

Association of social media use with smoking

Facebook was the preferred social media among the participants, with $73 \%$ using Facebook the most, $21.8 \%$ using YouTube the most, and 5.2\% choosing other forms of social media. Of the Facebook users, $30.1 \%$ were smokers, whereas significantly more $\left(44.3 \% ; \chi^{2}=9.105\right.$; $\mathrm{p}<0.05)$ of the YouTube group were smokers (table 2 ). The number of smokers was significantly higher among those who have used social media for more than 5 years compared with those who have used social media for 5 years or less $\left(\chi^{2}=9.420 ; \mathrm{p}<0.01\right)$ and among those who typically used social media at night rather than during the day $\left(\chi^{2}=6.728 ; p<0.01\right)$. There was also a significant association between tobacco advertising, promotion, and sponsorship (TAPS) activities on social media and smoking status of the participants. $\chi^{2}$ analyses showed that there were significantly more smokers out of those who shared
TAPS-related pictures or images on social media $(73.6 \%)$ than there were out of those who did not share TAPSrelated pictures or images $\left(13.3 \% ; \chi^{2}=218.517 ; \mathrm{p}<0.001\right)$. Similarly, the prevalence of smoking was higher among those who shared TAPS-related videos on social media $(74.6 \%)$ than out of those who did not share TAPS-related videos $\left(12.2 \% ; \chi^{2}=236.508 ; \mathrm{p}<0.001\right)$. Liking or following TAPS-related content was also significantly associated with smoking status (table 2).

Association of peer interaction with smoking

The number of hours and the typical time of day (day vs night) spent with peers were significantly associated with smoking status of participants (table 3). About half of the smokers spent 4 hours or more a day with peers, while only $35.3 \%$ of the non-smokers spent this same amount of time with peers $\left(\chi^{2}=12.373 ; \mathrm{p}<0.01\right)$. More smokers 
Table 3 Association of peer interaction with smoking

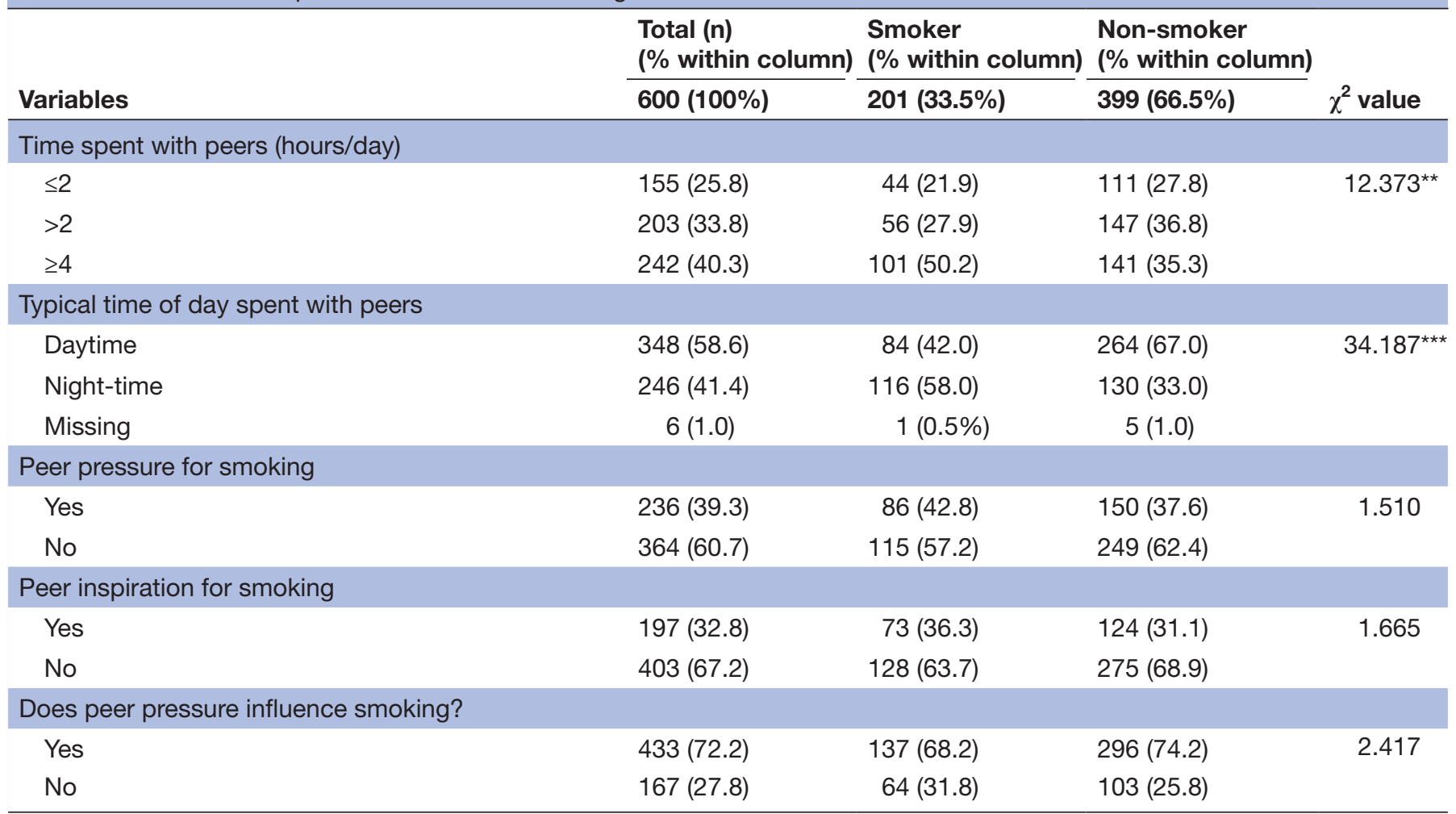

$\mathrm{n}=600$.

${ }^{* \star} \mathrm{P}<0.01 ;{ }^{* *} \mathrm{p}<0.001$.

$(58 \%)$ typically spent time at night with peers compared with non-smokers $\left(33 \% ; \chi^{2}=34.187 ; \mathrm{p}<0.001\right)$. Additionally, $72 \%$ of participants answered 'yes' when asked if peer pressure had a significant influence on smoking behaviour.

\section{Predictors of smoking}

Table 4 summarises the results of multivariate logistic regression analyses examining the associations between smokers and sociodemographic characteristics, social media use and peer interaction among participants. After adjusting for sociodemographic variables, including age, sex, living place and income status, male students had the greatest odds of smoking (OR 29.16, 95\% CI 10.55 to 80.69; model 2). These odds were higher after adjusting for social media use (OR 51.83, 95\% CI 15.26 to 176.06 ; model 3), but lower after adjusting for peer interaction (OR 23.50, 95\% CI 8.47 to 65.21; model 4).

\section{Social media use}

Students who prefer YouTube were associated with higher odds of smoking after adjusting for sociodemographic variables (OR 1.77, 95\% CI 1.15 to 2.75; model 2 ), as well as after adjusting for peer interaction (OR 1.86, $95 \%$ CI 1.22 to 2.83 ; model 4 ). Students who have used social media for more than 5 years have higher odds of smoking after adjusting for social media use (OR 2.03, $95 \%$ CI 1.12 to 3.69 ; model 3 ), as well as after adjusting for peer interaction (OR 1.65, 95\% CI 1.04 to 2.62; model 4). Students who use social media more at night have 2.41 (95\% CI 1.24 to 4.69 ; model 2 ) times the odds of being smokers than non-smokers after adjusting for sociodemographic variables. However, this OR decreased slightly after adjusting for variables related to peer interaction (OR 1.95, 95\% CI 1.02 to 3.73; model 4).

\section{Social media content interactions}

After adjusting for sociodemographic variables, the odds of being a smoker was 21.99 times (95\% CI 13.35 to 36.21 ; model 2) greater in those who shared TAPS-related images. After adjusting for social media use, this OR decreased to 4.95 (95\% CI 2.29 to 10.71 ; model 3) but was 16.90 (95\% CI 10.87 to 26.29; model 4) after adjusting for peer interaction. Similarly, those who shared TAPSrelated videos on social media had 23.94 times the odds (95\% CI 14.52 to 39.48; model 2) of being a smoker after adjusting for sociodemographic variables, an OR of 9.47 (95\% CI 4.21 to 21.31; model 3) after adjusting for social media use and an OR of 20.50 (95\% CI 13.02 to 32.26; model 4) after adjusting for peer interactions.

Social and peer interactions

Students who spent more than 4 hours / day with peers had 1.75 times higher odds of being a smoker after adjusting for sociodemographic variables (95\% CI 1.09 to 2.82; model 2) as well as after adjusting for peer interaction 
Table 4 Multivariate logistic regression analysis of the study variables

\begin{tabular}{|c|c|c|c|c|}
\hline \multirow[b]{2}{*}{ Variables } & Model 1* & Model $2 \dagger$ & Model 3¥ & Model 4§ \\
\hline & OR $(95 \% \mathrm{Cl})$ & OR $(95 \% \mathrm{Cl})$ & OR $(95 \% \mathrm{Cl})$ & OR $(95 \% \mathrm{Cl})$ \\
\hline \multicolumn{5}{|c|}{ Sociodemographic characteristics } \\
\hline $18-21$ & 1.00 & 1.00 & 1.00 & 1.00 \\
\hline $22-24$ & 1.27 (0.89 to 1.83$)$ & 1.15 (0.78 to 1.72$)$ & $1.32(0.81$ to 2.18$)$ & 1.26 (0.86 to 1.85$)$ \\
\hline $25-32$ & 1.37 (0.77 to 2.42$)$ & $1.28(0.68$ to 2.41$)$ & 2.00 (0.91 to 4.39$)$ & 1.08 (0.59 to 1.99$)$ \\
\hline Female & 1.00 & 1.00 & 1.00 & 1.00 \\
\hline Male & 28.12 (10.23 to 77.25$)$ & 29.16 (10.55 to 80.69$)$ & 51.83 (15.26 to 176.06$)$ & 23.50 (8.47 to 65.21$)$ \\
\hline \multicolumn{5}{|l|}{ Living place } \\
\hline With family & 1.00 & 1.00 & 1.00 & 1.00 \\
\hline No & $0.86(0.60$ to 1.24$)$ & $1.11(0.74$ to 1.67$)$ & $1.00(0.61$ to 1.63$)$ & 0.98 (0.66 to 1.45$)$ \\
\hline \multicolumn{5}{|c|}{ Social media use } \\
\hline \multicolumn{5}{|c|}{ Preferred social media: Facebook } \\
\hline No & 1.00 & 1.00 & 1.00 & 1.00 \\
\hline Yes & $0.58(0.40$ to 0.84$)$ & $0.54(0.36$ to 0.82$)$ & 0.97 (0.35 to 2.72$)$ & $0.56(0.38$ to 0.83$)$ \\
\hline \multicolumn{5}{|c|}{ Preferred social media: YouTube } \\
\hline No & 1.00 & 1.00 & 1.00 & 1.00 \\
\hline Yes & 1.81 (1.22 to 2.69$)$ & 1.77 (1.15 to 2.75$)$ & 2.12 (0.71 to 6.37$)$ & 1.86 (1.22 to 2.83$)$ \\
\hline \multicolumn{5}{|c|}{ Duration of social media use (years) } \\
\hline No & 1.00 & 1.00 & 1.00 & 1.00 \\
\hline Yes & 4.11 (2.87 to 5.88$)$ & 3.68 (2.50 to 5.42$)$ & 0.99 (0.51 to 1.92$)$ & 3.86 (2.65 to 5.62$)$ \\
\hline \multicolumn{5}{|c|}{$\begin{array}{l}\text { Shared TAPS-related } \\
\text { picture/image on social media }\end{array}$} \\
\hline No & 1.00 & 1.00 & 1.00 & 1.00 \\
\hline Yes & $18.23(11.90$ to 27.93$)$ & 21.99 (13.35 to 36.21$)$ & $4.95(2.29$ to 10.71$)$ & 16.90 (10.87 to 26.29$)$ \\
\hline \multicolumn{5}{|c|}{$\begin{array}{l}\text { Liked/followed TAPS-related } \\
\text { video on social media }\end{array}$} \\
\hline No & 1.00 & 1.00 & 1.00 & 1.00 \\
\hline Yes & 5.17 (3.59 to 7.46$)$ & 5.41 (3.62 to 8.09 ) & 0.59 (0.28 to 1.23$)$ & 4.85 (3.32 to 7.11$)$ \\
\hline \multicolumn{5}{|c|}{$\begin{array}{l}\text { Shared TAPS-related video } \\
\text { on social media }\end{array}$} \\
\hline No & 1.00 & 1.00 & 1.00 & 1.00 \\
\hline Yes & 21.27 (13.75 to 32.89$)$ & 23.94 (14.52 to 39.48$)$ & 9.47 (4.21 to 21.31$)$ & 20.50 (13.02 to 32.26$)$ \\
\hline \multicolumn{5}{|c|}{$\begin{array}{l}\text { Followed/joined any groups } \\
\text { related to smoking on social media }\end{array}$} \\
\hline No & 1.00 & 1.00 & 1.00 & 1.00 \\
\hline Yes & 3.10 (1.50 to 6.41$)$ & $2.79(1.26$ to 6.17$)$ & 3.30 (1.25 to 8.72$)$ & 2.88 (1.36 to 6.11$)$ \\
\hline \multicolumn{5}{|c|}{ Peer involvement } \\
\hline
\end{tabular}


Table 4 Continued

\begin{tabular}{|c|c|c|c|c|}
\hline & Model 1* & Model 2† & Model 3ł & Model 4§ \\
\hline Variables & OR $(95 \% \mathrm{Cl})$ & OR $(95 \% \mathrm{Cl})$ & OR $(95 \% \mathrm{Cl})$ & OR $(95 \% \mathrm{Cl})$ \\
\hline \multicolumn{5}{|c|}{ Time spent with peers (hours/day) } \\
\hline$>2$ & 0.96 (0.60 to 1.53$)$ & 0.89 (0.54 to 1.48$)$ & 1.12 (0.59 to 2.12$)$ & 0.88 (0.54 to 1.43$)$ \\
\hline$\geq 4$ & 1.81 (1.17 to 2.79$)$ & 1.75 (1.09 to 2.82$)$ & $1.75(0.96$ to 3.17$)$ & 1.75 (1.12 to 2.75$)$ \\
\hline Daytime & 1.00 & 1.00 & 1.00 & 1.00 \\
\hline Night-time & 2.80 (1.98 to 3.98$)$ & 2.11 (1.45 to 3.08$)$ & 2.40 (1.50 to 3.84$)$ & $2.80(1.95$ to 4.00$)$ \\
\hline \multicolumn{5}{|c|}{ Peer pressure for smoking } \\
\hline No & 1.00 & 1.00 & 1.00 & 1.00 \\
\hline \multicolumn{5}{|c|}{ Peer inspiration for smoking } \\
\hline \multicolumn{5}{|c|}{$\begin{array}{l}\text { Does peer pressure influence } \\
\text { smoking? }\end{array}$} \\
\hline No & 1.00 & 1.00 & 1.00 & 1.00 \\
\hline Yes & $\begin{array}{l}0.75 \\
(0.51 \text { to } 1.08)\end{array}$ & $\begin{array}{l}0.72 \\
(0.47 \text { to } 1.08)\end{array}$ & $\begin{array}{l}0.77 \\
(0.46 \text { to } 1.28)\end{array}$ & $\begin{array}{l}0.71 \\
(0.48 \text { to } 1.06)\end{array}$ \\
\hline
\end{tabular}

Boldface indicates a significance of $p<0.5$.

*Model 1 is unadjusted.

†Model 2 is adjusted for age, sex, living place and income status.

¥Model 3 is adjusted for all variables related to social media use.

$\S$ Model 4 is adjusted for all variables related to peer interactions.

TAPS, tobacco advertising, promotion and sponsorship.

variables (95\% CI 1.12 to 2.75 ; model 4). Spending time with peers at night also had significantly higher ORs after adjusting for sociodemographic variables (OR 2.11, 95\% CI 1.45 to 3.08; model 2), social media use (OR 2.40, 95\% CI 1.50 to 3.84; model 3) and peer interaction (OR 2.80, 95\% CI 1.95 to 1.66 ; model 4 ) .

\section{Qualitative findings}

The brief topic guide that was used focused on sharing experiences or insights related to social media and peer interactions on smoking. Two independent themes (influence of social media on smoking and impact of peer interactions on smoking) emerged from the interviews. The brief topic guide limited the interview to capturing the basic impact of social media and peer interactions on smoking behaviour that was beyond the reach of the structured quantitative measures. Due to time and resource constraints, it was not possible to have formal qualitative evaluations such as in-depth interviews and focus group discussions, which would have allowed an exploration of the different perceptions and thoughts related to factors underlying initiation or continuation of smoking.

Influence of social media on smoking

Participants spoke of how specific Facebook groups and short YouTube video clips aided in developing their fascination with smoking. Many participants expressed that the smoking mannerisms of popular male protagonists and even antagonists featured on social media influenced their attitudes towards smoking. One participant stated:

Some pictures and video clips of a show called 'Narcos' was shared on Facebook. The main and my favourite character was Pablo Escobar. He was a 'Godfather' figure and drug dealer who smoked most of the time with a unique style while leading a team of gangsters. I was very fascinated by that scene and imitated it several times.

One participant who mostly watched YouTube everyday said:

One day I was watching a movie on YouTube called 'Agantuk,' which was directed by Satyajit Ray. The hero was asked about the existence of god, at which point he put some tobacco in his pipe, lit it, then inhaled. I liked this scene very much.

Another participant contributed the initiation of their smoking behaviour to social media:

When I first started using Facebook, I viewed many beautiful pictures of smokers exhaling smoke using 
different styles like smoke rings, and it was the first time I was attracted to, and started, smoking.

This participant also stated that these first images of smokers were the main influence for him to continue using Facebook, as he wanted to look for more images like these.

Analysis of these quotes, along with others similar to these, reveals how portrayals of tobacco on social media like Facebook and YouTube drew the students in with attractive depictions of smoking, sometimes using a likable main character to show how 'cool' smoking is. Another theme that emerged was imitation-students copying the smoking behaviour of characters they connected with on social media. Quotes like these help to explain how social media can influence smoking behaviour in this age group.

\section{Influence of peer interactions on smoking}

When asked about the influence of face-to-face peer interactions on smoking behaviour, one participant attributed his initial desire to smoke to a combination of exposure to friends smoking in his proximity and to peer pressure during a difficult time in his life:

We arranged a picnic together. There were many friends who smoked. I was slightly affected by them.

I thought, 'if they can do it, why not me'; and so, I

did too. Moreover, there was another issue-I was frustrated at the time with a personal issue and my friends advised that smoking will heal me.

Other participants shared similar statements as this on the topic of peer interactions and smoking. They mentioned that friends insisted they try the 'experience' for the first time, provided the first few cigarettes or suggested that they take up smoking during a vulnerable period, such as during a break-up, after failing an examination, or during a financial crisis. Analysis of this portion of the interview revealed a theme of friends and peers being involved with the participants' first instance of tobacco use, suggesting that face-to-face peer interactions can also greatly influence smoking behaviour in students.

\section{DISCUSSION}

This study suggests that social media and peer group involvement are associated with tobacco smoking among university students in an urban setting of Dhaka, Bangladesh. This finding is consistent with the literature that peer group interaction and social media play a key role in determining smoking behaviour. ${ }^{29}$ Tobacco smoking is widely practised in Bangladesh, especially among adults. Adolescents and young adults are the most vulnerable groups for tobacco smoking. ${ }^{30-32}$ The overall prevalence estimate of tobacco smoking among university students in the urban Dhaka region was $33.5 \%$. A recently published article suggests that the prevalence estimate of this study is slightly lower than the prevalence estimate of $37 \%$ among university students in the Sylhet region. ${ }^{13}$ However, the Global Adult Tobacco Survey (GATS) found that the overall prevalence rate of tobacco smoking in Bangladesh was $18.0 \%$, which suggests there is a higher prevalence of smoking among university students in Dhaka, Bangladesh, than among adults in general. ${ }^{9}$ In this study, $43.7 \%$ of the male participants were smokers, which is also higher than the adult male prevalence reported in the GATS study. ${ }^{9}$ Similarly, the smoking prevalence among male students of this study was higher than the prevalence estimates for India (20.4\%), Pakistan (26.1\%), ${ }^{29} 2133$ Nepal $(33.6 \%)$ and Malaysia $(41.2 \%)$, but lower than another study conducted in Bangladesh (68.0\%). ${ }^{16}{ }^{33-36}$ This suggests that smoking prevalence among male students in Bangladesh may be among the highest in Southeast Asian countries.

The role of social media as an influence on attitudes towards tobacco use among Bangladeshi university students has been largely overlooked until now, and no study was found that researched this association in Bangladeshi youth. The current study investigated this relationship for the first time and found a strong association between social media use and students' tobacco consumption. However, echoing a previous study, our study found that Facebook use had lower odds on students' smoking behaviour. ${ }^{37}$ Although Facebook use lowered the students' odds of smoking, use of YouTube was associated with higher odds of smoking. Studies who have performed content analyses on social media, especially YouTube and Facebook, have found that tobaccorelated materials are ample and dominantly positive in its portrayal of tobacco use..$^{38-46}$ One of the potential reasons behind this overabundance of tobacco-related content on social media is that after legislative bans on TAPS came into effect, the tobacco industries pushed to use social media as a tool to keep their products in the minds of current and potential tobacco consumers. ${ }^{29} 47$ This tobacco content on social media has a great negative impact on the behaviour of youth and young adults. ${ }^{48}$ Furthermore, this advertising influenced the initiation and continued the use of tobacco among them. ${ }^{50-52}$ Consistent with previous studies, this study also suggests that use of social media, including sharing and liking tobacco-related content, is associated with smoking. ${ }^{39} 5354$ This study also suggests that long-term engagement with social media is associated with smoking, as participants who have been using social media for 5 years or more had almost two times the odds of being smokers than those who have been using social media for less than 5 years. In addition, our study suggests that students who use social media typically during the night-time had more than two times the odds of smoking than that of students who used social media typically during the daytime.

Peer involvement was also found to be strongly associated with smoking in this study. Results suggest that students who spent more than 4 hours/day with friends had almost two times the odds of smoking than those who spent less than 2 hours/day with friends. This finding 
supports the theory that unstructured peer socialisation has a delinquency-facilitating effect on behaviour. ${ }^{55}$ Furthermore, our study suggests that peer socialisation at night was more associated with tobacco smoking than socialisation during the daytime; students who spent their time with peers more often at night had more than two times the odds of being a smoker than those who spent the daytime more often with their peers.

\section{Limitations}

The cross-sectional nature of this study limits the conclusions that can be drawn in regard to establishing cause and effect. Longitudinal designs need to be conducted in the future to guide the creation of interventions. Despite the widespread use of tobacco products in Bangladesh, smoking may still carry stigma. Thus, another limitation is the potential for reporting bias during data collection. Although the study sample was collected from both public and private universities, the sample is not representative of all students in Bangladesh, or all youth in the country. Results may not be generalisable to these other populations.

\section{CONCLUSION}

This study suggests a high prevalence of smoking tobacco among university students in Dhaka, Bangladesh, which is emerging as a major public health concern in the country. Findings also suggest the initiation and continuation of smoking may be influenced by peers and social media, which are novel findings for this context. Future largescale research should continue to investigate the roles social media and peer interaction have on smoking, as well as intervention methods to decrease smoking among this population. For example, social media may also be harnessed to encourage smoking cessation. Smoking cessation counselling, awareness programmes and warnings about the health hazards of smoking might also be disseminated and shared through social media. Nonetheless, decreasing both the proliferation of tobacco content on social media and the negative effects tobacco content has on university students should be a topic of discussion among health policymakers and officials regulating government censorship.

\section{Author affiliations}

${ }^{1}$ Department of Public Health, North South University, Dhaka, Bangladesh

${ }^{2}$ Public Health Foundation, Bangladesh (PHF,BD), Dhaka, Bangladesh

${ }^{3}$ Department of Primary Care and Mental Health, University of Liverpool, Liverpool, UK

${ }^{4}$ Department of Public Health and Informatics, Jahangirnagar University, Savar, Dhaka, Bangladesh

${ }^{5}$ Center for Population and Development Studies, Harvard T H Chan School of Public Health, Cambridge, Massachusetts, USA

${ }^{6}$ Gynecology and Obstetrics, Shaheed Suhrawardy Medical College and Hospital, Dhaka, Bangladesh

Twitter Naym Uddin Roby @ny_roby

Acknowledgements We are thankful to the Bangladesh Centre for Communication Programs (BCCP) for their intensive technical assistance to conduct this study which included field implementation, study tool validation, data processing and data analysis. The data collectors SH, Farina Tabassum, Rubya Islam, Tanjim Sharif and Sonia Islam worked incredibly hard to collect quality data which made the research more robust within the limited time frame. We are also thankful to the administration of Dhaka University, Jahangirnagar University, American International University-Bangladesh and North South University for the permission to collect the data from students and use their premises during qualitative data collection.

Contributors NUR conceptualised the study, drafted the protocol, developed the tools, trained the RAs, conducted qualitative interviews and prepared the report and manuscript. MTH edited the protocol and tools, drafted the topic guide, trained the RAs and drafted the manuscript. NUR and MTH equally contributed to this manuscript. SH prepared the tables and reviewed the results. EC critically reviewed and edited the manuscript. MKA, ABC and SH reviewed the tools and provided input for reporting and analysis. FA contributed to the protocol and overall supervision of research activities, and critically reviewed the manuscript.

Funding This study was funded by the Institute of Global Tobacco Control and the Johns Hopkins Bloomberg School of Public Health, and supported by Bangladesh Centre for Communication Programs (GC\#BCCP/Tobacco Control/2017-18).

\section{Competing interests None declared.}

Patient consent for publication Not required.

Ethics approval Ethical clearance was obtained from the Ethical Review Board of North South University, Dhaka, Bangladesh (178074). Formal administrative permission from each participating institute was also taken.

Provenance and peer review Not commissioned; externally peer reviewed. Data availability statement Data are available upon reasonable request.

Open access This is an open access article distributed in accordance with the Creative Commons Attribution Non Commercial (CC BY-NC 4.0) license, which permits others to distribute, remix, adapt, build upon this work non-commercially, and license their derivative works on different terms, provided the original work is properly cited, appropriate credit is given, any changes made indicated, and the use is non-commercial. See: http://creativecommons.org/licenses/by-nc/4.0/.

\section{ORCID iDs}

Naym Uddin Roby http://orcid.org/0000-0002-3512-2687

Sahadat Hossain http://orcid.org/0000-0001-9433-202X

\section{REFERENCES}

1 WHO. Who global report on trends in prevalence of tobacco smoking, 2015. Available: https://apps.who.int/iris/bitstream/handle/ 10665/156262/9789241564922_eng.pdf;jsessionid=18318DE7B3C3 CE50967CF3B71C8B4B5D? sequence $=1$

2 Mathers CD, Loncar D. Projections of global mortality and burden of disease from 2002 to 2030. PLoS Med 2006;3:e442-30.

3 Commar A, Prasad VK, Weltgesundheitsorganisation. Who global report on trends in prevalence of tobacco smoking 2000-2025. 121 p., 2018. Available: https://www.who.int/tobacco/publications/ surveillance/trends-tobacco-smoking-second-edition/en/

4 Crone MR, Reijneveld SA. The association of behavioural and emotional problems with tobacco use in adolescence. Addict Behav 2007;32:1692-8.

5 Barra C L, Fernández P P, Granada G F, et al. [Smoking among undergraduate university students]. Rev Med Chil 2015;143:1343-50.

6 Karadoğan D, Kanbay Y, Ö Önal, et al. Prevalence and determinants of cigarette smoking among university students. Eur Respir J 2018;52:PA4562.

7 Khami MR, Murtomaa H, Razeghi S, et al. Smoking and its determinants among Iranian dental students. Med Princ Pract 2010;19:390-4.

8 Nazary AA, Ahmadi F, Vaismoradi M, et al. Smoking among male medical sciences students in Semnan, Islamic Republic of Iran. East Mediterr Health J 2010;16:156-61.

9 Bangladesh Bureau of Statistics, Government of the People's Republic of Bangladesh, WHO Bangladesh and CDC U. Global adult tobacco survey Romania, 2017. Available: http://www.searo.who.int/ bangladesh/gatsbangladesh2017fs14aug2018.pdf?ua=1

10 Jubayer S, Choudhury SR, Al Mamun MA, et al. Effect of community based tobacco cessation intervention in a rural community of Bangladesh. Tob Induc Dis 2018;16.

11 Sultana P, Rahman MT, Roy DC, et al. Tobacco control policies to promote awareness and smoke-free environments in residence and 
workplace to reduce passive tobacco smoking in Bangladesh and its correlates. PLoS One 2018;13:e0198942.

12 Barkat A, Uddin Chowdhury A, Nargis N, et al. The economics of tobacco and tobacco taxation in Bangladesh, 2012. Available: http:// www.tobaccofreeunion.org/content/en/217/

13 Hassan MS, Hossain MK, Khan HTA. Prevalence and predictors of tobacco smoking among university students in Sylhet division, Bangladesh. Int Health 2019;11:306-13.

14 Bayat M, Pillay BJ, Cassimjee MH. Cigarette smoking behavior among South African Indian high school students. J Family Community Med 1998;5:51.

15 Leshargie CT, Alebel A, Kibret GD, et al. The impact of peer pressure on cigarette smoking among high school and university students in Ethiopia: a systemic review and meta-analysis. PLoS One 2019;14:e0222572.

16 Hossain S, Hossain S, Ahmed F, et al. Prevalence of tobacco smoking and factors associated with the initiation of smoking among university students in Dhaka, Bangladesh. Cent Asian J Glob Health 2017;6:244

17 Sabbir Ahmed M. Prevalence and factors associated with cigarette smoking among resident university students: a cross-sectional study from Bangladesh. Popul Med 2020;2.

18 (BTRC) Bangladesh TRC. Internet subscribers. Available: http://www. btrc.gov.bd/content/internet-subscribers-bangladesh-november2019

19 Liang Y, Zheng X, Zeng DD, et al. Exploring how the tobacco industry presents and promotes itself in social media. $J$ Med Internet Res 2015;17:e24.

20 Trade Commission F. Federal Trade Commission cigarette report for 2014. 31, 2015. https://www.ftc.gov/system/files/documents/reports/ federal-trade-commission-cigarette-report-2014-federal-tradecommission-smokeless-tobacco-report/ftc_cigarette_report_2014. pdf

21 Can M, Gökçe SA. The use of social networks among university students. Educ Res Rev 2019;14:190-9.

22 Dube SR, Arrazola RA, Lee J, et al. Pro-tobacco influences and susceptibility to smoking cigarettes among middle and high school students--United States, 2011. J Adolesc Health 2013;52:S45-51.

23 Robalino JD. Smoking Peer Effects among Adolescents : Are Popular Teens More Influential? Discuss Pap 2016; IZA Discussion Paper No. 9714:1-12.

24 Urberg KA, Shyu SJ, Liang J. Peer influence in adolescent cigarette smoking. Addict Behav 1990;15:247-55.

25 Sultana P, Akter S, Akter S, et al. Prevalence and predictors of current tobacco smoking in Bangladesh. Journal of Biostatistics and Biometric Applications 2016;1:1-8.

26 Regulations S, Act S. Ministry of health and family welfare. Regulation. , 2010: 36(7), 410-776.

27 Government of Bangladesh, World Health Organisation Country Office for Bangladesh, Centers for Disease Control and Prevention (CDC) Atlanta USA. Global adult tobacco survey (GATS) fact Sheet-2009, 2009. Available: http://www.who.int/tobacco/ surveillance/fact sheet of gats bangladesh 2009.pdf

28 Williams JR. Bulletin of the world Health organization. The Declaration of Helsinki and public health. World Health Organization, 2008. Available: /pmc/articles/PMC2649471/?report=abstract [Accessed $1 \mathrm{Jul}$ 2020].

29 McCool J, Freeman B, Tanielu H. Perceived social and media influences on tobacco use among Samoan youth. BMC Public Health 2014;14:1100.

30 Anjum A, Hossain S, Sikder T, et al. Investigating the prevalence of and factors associated with depressive symptoms among urban and semi-urban school adolescents in Bangladesh: a pilot study. Int Health 2019;inz092:1-9.

31 Hossain S, Hossain MS, Anjum A, et al. Risk modeling of noncommunicable diseases using socio-demographic characteristics, lifestyle and family disease history among university students in Bangladesh. J Public Health 2018;26:531-43.

32 Hossain S, Anjum A, Uddin ME, et al. Impacts of socio-cultural environment and lifestyle factors on the psychological health of university students in Bangladesh: a longitudinal study. J Affect Disord 2019;256:393-403.
33 Asif HM, Akhtar N, Sultana S. Prevalence and FactorsRelated to cigarette smoking initiation and use among university students of Bahawalpur Pakistan: a cross sectional study. RADS J Pharm Pharm Sci 2017;5(3:11-16.

34 Pradhan PMS, Niraula SR, Ghimire A, et al. Tobacco use and associated factors among adolescent students in Dharan, eastern Nepal: a cross-sectional questionnaire survey. BMJ Open 2013;3:e002123-7.

35 Al-Naggar RA, Bobryshev YV, Mohd Noor NAB. Lifestyle practice among Malaysian university students. Asian Pac J Cancer Prev 2013;14:1895-903.

36 Lalithambigai G, Rao A, Rajesh G, et al. Predictors of cigarette smoking among young adults in Mangalore, India. Asian Pac $J$ Cancer Prev 2016;17:45-50.

37 Huang GC, Soto D, Fujimoto K, et al. The interplay of friendship networks and social networking sites: longitudinal analysis of selection and influence effects on adolescent smoking and alcohol use. Am J Public Health 2014;104:e51-9.

38 Bromberg JE, Augustson EM, Backinger CL. Portrayal of smokeless tobacco in YouTube videos. Nicotine Tob Res 2012;14:455-62.

39 Duke JC, Allen JA, Pederson LL, et al. Reported exposure to protobacco messages in the media: trends among youth in the United States, 2000-2004. Am J Health Promot 2009;23:195-202.

40 Elkin L, Thomson G, Wilson N. Connecting world youth with tobacco brands: YouTube and the Internet policy vacuum on web 2.0. Tob Control 2010;19:361-6.

41 Carroll MV, Shensa A, Primack BA. A comparison of cigarette- and hookah-related videos on YouTube. Tob Control 2013;22:319-23. Sep;.

42 Kim K, Paek H-J, Lynn J. A content analysis of smoking fetish videos on YouTube: regulatory implications for tobacco control. Health Commun 2010;25:97-106.

43 Luo C, Zheng X, Zeng DD. Portrayal of electronic cigarettes on YouTube. In: Lecture notes in computer science (including Subser Lect notes Artif Intell Lect notes bioinformatics. , 2013: 8040, 1-6.

44 Richardson A, Vallone DM. Youtube: a promotional vehicle for little cigars and cigarillos? Tob Control 2014;23:21-6.

45 Romer D, Jamieson PE, Jamieson KH, et al. Counteracting the influence of peer smoking on YouTube. $J$ Health Commun 2017;22:337-45.

46 Seidenberg AB, Rodgers EJ, Rees VW, et al. Youth access, creation, and content of smokeless tobacco ('dip') videos in social media. $J$ Adolesc Health 2012;50:334-8.

47 Freeman B, Chapman S. Is 'YouTube' telling or selling you something? Tobacco content on the YouTube video-sharing website. Tob Control 2007;16:207-10.

48 Donaldson EA, Hoffman AC, Zandberg I, et al. Media exposure and tobacco product addiction beliefs: findings from the 2015 health information national trends survey (HINTS-FDA 2015). Addict Behav 2017:72:106-13.

49 Yoo W, Yang J, Cho E. How social media influence college students' smoking attitudes and intentions. Comput Human Behav 2016;64:173-82.

50 Kuipers MA, Best C, Wilson M, et al. Adolescents' perceptions of tobacco accessibility and smoking norms and attitudes in response to the tobacco point-of-sale display ban in Scotland: results from the display study. Tob Control 2020;29:348-56.

51 Kreitzberg DS, Herrera AL, Loukas A, et al. Exposure to tobacco and nicotine product advertising: associations with perceived prevalence of use among college students. J Am Coll Health 2018;66:790-8.

52 Richardson A, Ganz O, Vallone D. Tobacco on the web: surveillance and characterisation of online tobacco and e-cigarette advertising. Tob Control 2015;24:341-7.

53 Jamieson PE, Romer D. Trends in US movie tobacco portrayal since 1950: a historical analysis. Tob Control 2010;19:179-84.

54 Villanti A, Boulay M, Juon H-S. Peer, parent and media influences on adolescent smoking by developmental stage. Addict Behav 2011;36:133-6.

55 Meldrum RC, Clark J. Adolescent virtual time spent socializing with Peers, substance use, and delinquency. Crime \& Delinquency 2015;61:1104-26. 